\title{
Simulasi Proteus Atap Stadion Automatic Berbasis Arduino Dengan Menggunakan Sensor Hujan Dan Sensor LDR
}

\author{
Ahmad Fauzan \\ Program Studi, Teknik Elektro, Universitas Trunojoyo Madura, Bangkalan \\ Ahmadfauzan@gmail.com
}

\begin{tabular}{l} 
Article Info \\
\hline Article history: \\
Received September $12^{\text {th }}, 2021$ \\
Revised October $10^{\text {th }}, 2021$ \\
Accepted October $16^{\text {th }}, 2021$
\end{tabular}

\section{Keyword:}

Climate Change

Atmega 328P

Microcontroller

LDR sensor

Rain sensor

\begin{abstract}
Tropical climate change in Indonesia that often experiences prolonged rain conditions, making it very difficult to know the weather will rain and sunny weather. This is often a problem for the organizers of football events, especially in Indonesia during the rainy season is heavy enough to prolong that causes puddles of rain water on the football field to block a match that causes a temporary stop on the match. Therefore, there needs to be new innovations, by utilizing the technology that is growing today there needs to be an automatic open-close roof system for the sake of comfort in match flares, using LDR sensors and rain sensors installed around the roof of the stadium. The LDR sensor will read the light and dark conditions, the LDR sensor will also activate the stadium lights when it is dark, while the rain sensor will detect rain when receiving water droplets with a value of less than $300 \mathrm{RH}$ that will be read on the LCD, then the mootor will be active and close the roof of the Stadium but conversely when the rain sensor receives water droplets more than 300RH on the LCD then automatically the roof of the stadium will open again. Both sensors are controlled by the Atmega 328P microcontroller system. When the microcontroller receives input from rain sensors and LDR sensors, the microcontroller processes and sends data to the motor driver to open or close the roof of the stadium automatically and blame the stadium lights on dark conditions. The system can also be controlled manually and automatically. The manual in question is the opening of the lid on the roof of the stadium that is controlled directly by humans.
\end{abstract}

Copyright () 2021 Jurnal JEETech. All rights reserved.

\section{Corresponding Author:}

Ahmad Fauzan

Program Studi, Teknik Elektro, Universitas Trunojoyo Madura, Bangkalan

Ahmadfauzan@gmail.com

Abstrak-Perubahan iklim tropis di indonesia yang sering mengalami kondisi hujan yang bekepanjangan, sehingga sangat sulit untuk mengetahui cuaca akan hujan dan cuaca cerah. Hal ini sering menjadi permasalahan bagi penyelnggara event sepak bola terutama di Indonesia pada saat musim hujan cukup deras bekepanjangan sehingga menyebabkan genangan air hujan pada lapangan sepak bola menghabat suatu pertandingan yang menyebabkan pemberhentian sementara pada petandingan. Maka dari itu perlu adanya inovasi baru, dengan memanfaatkan teknologi yang semakin berkembang saat ini perlu adanya sebuah system atap buka tutup otomatis demi kenyaman pada suartu pertandingan, dengan menggunakan sensor LDR dan sensor hujan yang terpasang disekitar atap stadion. Sensor LDR akan membaca kondisi cahaya terang dan gelap, sensor LDR juga akan mengaktifkan lampu stadion apabila kondisi gelap, sedangkan sensor hujan akan mendeteksi turunya hujan Ketika menerima tetesan air dengan nilai kurang dari $300 \mathrm{RH}$ yang akan terbacapa pada LCD, maka mootor akan aktif serta menutup atap stadion, namun sebaliknya Ketika sensor hujan menerima tetesan air lebih dari 300RH pada LCD maka secara otomatis atap stadion akan terbuka Kembali. 
Kedua sensor tersebut dikendalikan oleh system mikrokontroler Atmega 328P. Pada saat mikrokontroler menerima input dari sensor hujan dan sensor LDR, maka mikrokontroler memproses dan mengirim data ke driver motor untuk membuka atau menutup atap stadion secara otomatis serta menyalahkan lampu stadion pada kondisi gelap. Sistem tersebut juga bisa dikendalikan secara manual dan otomatis. Manual yang dimaksudh merupakan buka tutup pada atap stadion yang dikontrol langsung oleh manusia.

\section{Kata Kunci-Perubahan Iklim,Mikrokontroler Atmega $328 P$ sensor LDR, Sensor hujan}

\section{PENDAHULUAN}

Perubahan iklim tropis di Indonesia yang terjadi akhir-akhir ini menjadi sebuah pergantian musim yang kurang stabil. Sehingga menyebabkan kondisi cuaca yang sulit diprediksi, dimana hal ini masih menjadi permasalahan penyelnggara event sepak bola sedikit kawatir dalam dalam suatu pertandingan terutama saat cuaca yang tidak menentu.Pada kondisi cuaca hujan yang berkepanjangan dimana dapat menyebabkan genangan air yang sangat luar biasa sehingga terjadinya pemberhetian pertandingan karena cuaca yang tidak memungkinkan suatu pertandingan dilanjutkan begitupn dengan penonton merasakan ketidak nyamanan dalam menyaksikan suatu pertandingan karena kehujanan. Hal ini menjadi sebuah perhatian khusus bagi penyelenggara event sepak bola ditanah air agar suatu pertandingan berjalan dengan lancar tampa hambatan dan kendala apapun. Keadaan lapangan sepak bola di negara-negara maju tersebut, bisa menjadi acuan agar lapangan yang bagus. Sehingga Ketika terjadinya hujan, lapangan tersebut tidak menganggu laju pada bola dan lapangan tetap dapt digunakan untuk menjalani pertandingan.

Melihat kondisi diatas melalui sebuah inovasi Melalui inovasi perancangan atap stadion otomatis ini dengan system buka tutup memiliki kelebihan dibandingkan yang bisa akita lihat biasanya, salah satunya semua system ini tidak hanya dikendalikan manual saja namun bisa semuanya dilakukan secara otomatis. Prinsip kerja system atap stadion ini akan menutup atap secara otomatis apabila terjadi turun hujan dan pada saat kondisi atap tertutup maka secara otomatis pula lampu akan menyala. Atap stadion akan terbuka secara otomatis Kembali apa bila hujan sudah berhenti dengan memberikan jeda waktu selama 5 menit.Hal ini mampu mengatasi permasalahan kondisi lapangan tidak cepat rusak dan memberikan kenyaman bagi orangorang yang berada di dalam stadion pada suatu pertandingan yang sedang berlangsung.

Sistem atap stadion otomatis ini dibuat dengan menggunakan Arduino,motor stepper,Sensor LDR dan sensor hujan. Pada system ini terdapat program yang mengatur buka tutup atap stadion dalam kondisi cuaca panas, malam hari dan hujan deras akan menutup secara otomatis. Stadion yang bisa dikatakan modern ini dapat mengikuti cuaca yang sangat memberikan kenyaman pada penonton dan para pemain yang sedang bertanding dilapangan..

LDR (Light Dependent Resistor) cara kerja dari LDR sendiri adalah apabila kondisi cahaya terang maka suatu nilai hambatannya menjadi kecil bahkan dapat menyentuh angka nol tegantung pada intensitas cahaya yang menerangi LDR tersebut dan apa bila gelap maka hambatannya menjadi semakin besar (Suryanto \& Atmaja,2017).[1]

Sensor ini mengubah energi foton menjadi electron. Sensor ini juga mempunyai kegunaan yang sangat luas sekali, salah satunya adalah sebagai pendeteksi cahaya pada atap stadion otomatis. Beberapa komponen yang biasanya digunakan rangkaian sensor cahaya adalah LDR, PhotodiodeI, dan Photo Transistor. (Hurriyatul \& Widasari,2017) klasifikasi sinyal berdasarkan nilai data dibedakan menjadi sinyal analog dan digital, sinyal analog memiliki sinyal data kontinyu data dalam bentuk pulsa dengan bilangan biner ( 0 dan $1)$.
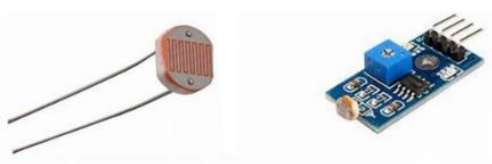

Gambar 1. Sensor LDR

(sumber.belajaronline.net) 
(Siswanto 7 winardi, 2015) Sensor Hujan merupakan alat Switching yang digerakkan berdasarkan curah hujan (air). Sensor ini digunakan mendeteksi dan mengetahui magnitude tertentu. Sensor air hujan dibuat dengan memanfaatkan konduktivitas air hujan, apabila terkena air hujan mengenai panel pada sensor maka terjadi proses elektrolisasi oleh air tersebut [2]. (Ishak,2019) Sensor air hujan berfungsi untuk memberikan nilai masukan pada tingkat elektrolisasi air, dimana air akanmenyentuh panel sensor air. Untuk menghindari karat atau tertutup kotoran yang menyebabkan sensor tidak bekerja, jalur tersebut harus dilapisi timah atau apa saja yang dapat menyatu dengan jalur tersebut dan dapat menghantarkan arus listri. Prinsip kerja dari module sensor ini yaitu pada saat ada air hujan turun dan mengenai panel sensor maka akan terjadi proses elektrolisasi oleh air hujan. Dan karena air hujan termasuk dalam golongan cairan elektrolit yang dimana cairan tersebut akan menghantarkan arus listrik

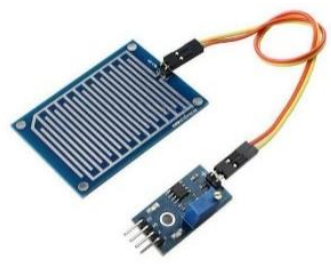

\section{Gambar 2. Motor stepper}

(sumber.nyebarilmu.com)

Arduino Merupakan Sistem minimum Mikrokontroler yang mempunyai sifat open source (gratis lisensi software). Pada Arduiono Nano digunakan IC Mikrokontroler ATMega 328P (Arduino Nano 3.0). Selain bersifat Open Source Arduino juga memiliki Bahasa Pemograman sendiri berupa Bahasa C. Arduino Nano memiliki DC Power jack, port USB Mini-B yang digunakan untuk upload source code Program ke-dalam mikrokontroler.Komponen utama yang berfungsi sebagai otak dari segala macam kegiatan alat ini dikendalikan oleh Mikrokontroler.[3] Mikrokontroler merupakan komputer yang berukuran mikro dalam satu chip IC (integrated Circuit) yang terdiri dari processor,memory, dan antarmuka yang bisa deprogram.
Jadi disebut computer mikro karena dalam IC atau Chip mikrokontroler terdiri dari CPU, memory, dan I/O yang bis akita control dengan memprogramnya (Santoso,2015).

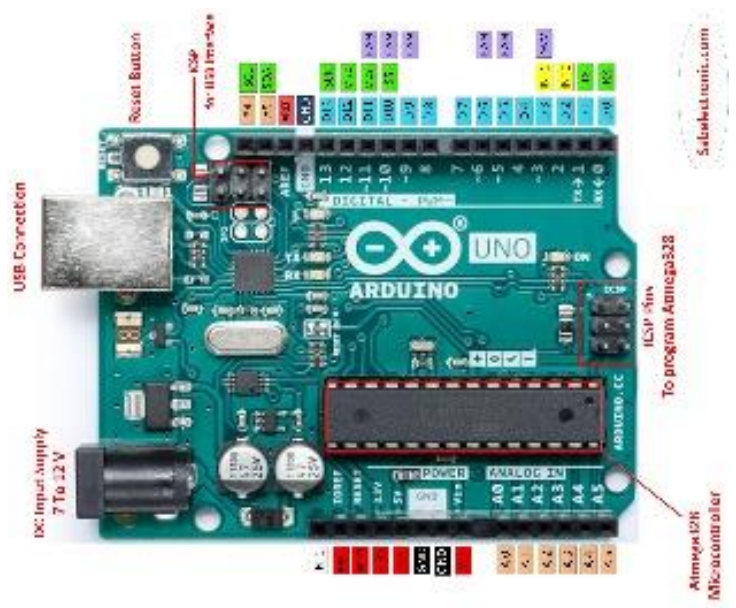

Gambar 3. Arduino uno

(sumber 3. Arduino.cc)

Motor stepper merupakan salah satu jenis motor yang banyak digunakan ini sebagai actuator, misalnya sebagai bagai penggerak baca/tulis pada disk drive yang akan menetapkan posisi, dengan bantuan mikroprosesor atau mikrokontroler perutaran motor dapat dikontrol dengan tepat dan terprogram.(syahru,2018). Suatu motor listrik yang dapat mengubah pulsa listrik yang diberikan menjadi Gerakan motor discret (terputus) yang disebut step (Langkah). Suatu putaran motor memerlukan 360 dengan jumlah Langkah yang tertentu per-derajatnya. Ukuran kerja dari motor stepper biasanya diberikan dalam jumlah Langkah perputaran per-detik [4]

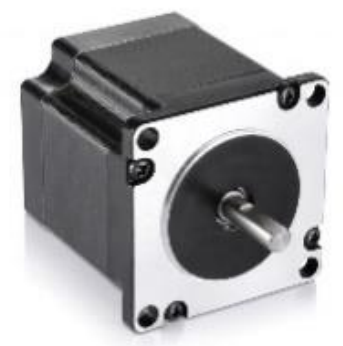

Gambar 4.Motor stepper

(sumber.jagootomasi.com) 
Rangkaian pengendali motor stepper (Stepper motor driver) menggunakan komponen utama berupa sebuah IC A3967SLBT, yaitu rangakain Driver sederhana untuk mengendalikan motor stepper jenis bipolar sumber tegangan mulai dari 6V sampai $30 \mathrm{~V} \mathrm{DC}$, dan biasanya driver ini digunakan pada motor bipolar dengan 4,6 atau kawat.[5]

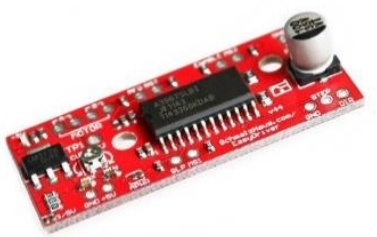

Gambar 5. Stepper motor driver

(Sumber.electropeak.com)

Power Supply alat listrrik dapat menyediakan energi listrik untuk perangkat listrik ataupun elektronika lainnya. Pada dasarnya power supply atau Catu day aini memerlukan sumber energi listrik yang kemudian mengubahnya menjadi energi listrik yang dibutuhkan oleh perangkat elektronika lainnya. Oleh karena itu power supply kadang-kadang disebut dengan istilah electric Power Converter.[6]

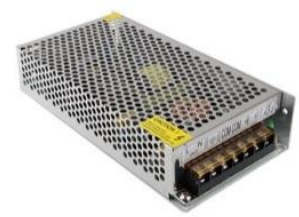

Gambar 6. Power Supply

(sumber.circuitspesialists.com)

Realay adalah saklar (Switch) yang dioperasikan secara listrik dan merupakan komponen Electromechanical yang terdiri dari 2 bagian utama yakni electromagnet (Coil) dan Mekanikal (Seperangkat kontak Saklar/Switch). Relay menggunakan prinsip Elektromagnetik untuk menggerakkan kontak saklar sehingga dengan arus listrik yang kecil (Low Power) dapat menghantarkan listrik [7]

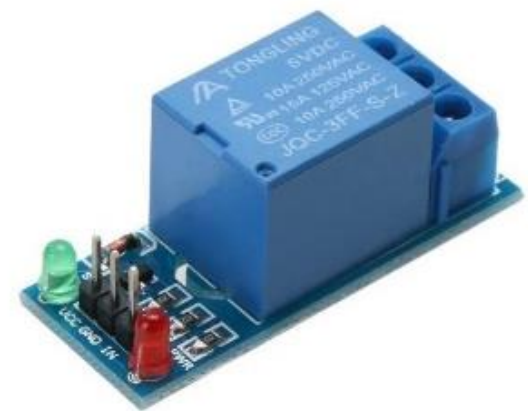

Gambar 7. Relay

(sumber.arduinogetstarted.com)

Push Button Switch (Saklar tombol tekan) adalah perangkat / saklar sederhana yang berfungsi untuk menghubungkan atau memutuskan aliran arus listrik dengan system kerja tekan, untuk project ini digunakan untuk mengirimkan perintah berupa logic gate ke Arduino nano [8]

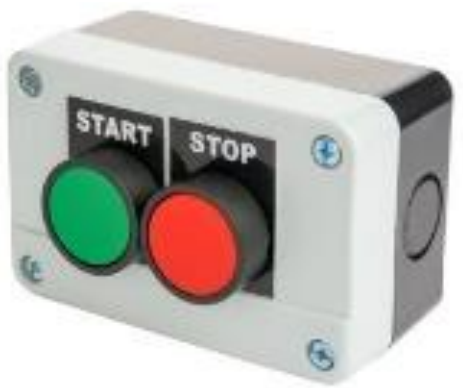

Gambar 8. Stepper motor driver

(Sumber.shutterstock.com)

Arduino IDE merupakan kependekan dari Integrated development Eviroenment, atau secara Bahasa mudahnya merupakan lingkungan integrasi yang digunakan untuk melakukan pengembangan. Disebut sebagai lingkungan karena melalui Software inilah Arduino dilakukan pemrograman melalui sintaks pemrograman.arduino dilakukan pemorograman untuk melakukan fungsi-fungsi yang dibenamkan melalui sintaks permrograman. Arduino (sketcet) sudah dilakukan perubahan untuk memudahkan pemula dalam melakukan pemrograman dari Bahasa aslinya [9]

Proteus merupakan sebuah software yang digunakan untuk mendesain PCB yang juga dilengkapi dengan simulasi PSpice pada skematik sebelum 
rangakain skematik di-Upgrade ke PCB untuk memastikan PCB dapat berfungsi dengan semsetinya.Proteus mengkombinasikan Program ISIS untuk membuat sjematik desain rangkain dengan Prpgram ARES untuk membuat layout PCB dari skematik yang dibuat [10]

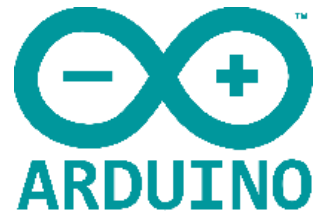

Gambar 9. Arduino IDE (sumber.arduino.cc) Crackwebsite.com)

\section{METODE PENELITIAN}

A. $\quad$ Metode

Dalam penelitian ini, penulis menggunakan beberapa

7metode yaitu:

1. Studi Pustaka

Dalam rangka mencari materi sumber referensi yang baik, maka penulis melakukan dengan metode studi Pustaka, yaitu dengan mencari informasi dari jurnal, artikel ilmiah,buku dan internet yang terkait dengan penelitian

2. Eksperimen

Kegitan ini digunakan oleh penulis sebagai tahap lanjut dari informasi yang telah didapatkan, yaitu dimulai dari tahap desain gambar layout, kemudian dilanjutkan dengan proses membuat alat dengan komponen yang dibutuhkan, kemudian melakukan uji coba dan troubleshooting terhadap alat yang dibuat.
B. Gambar Diagram Blok

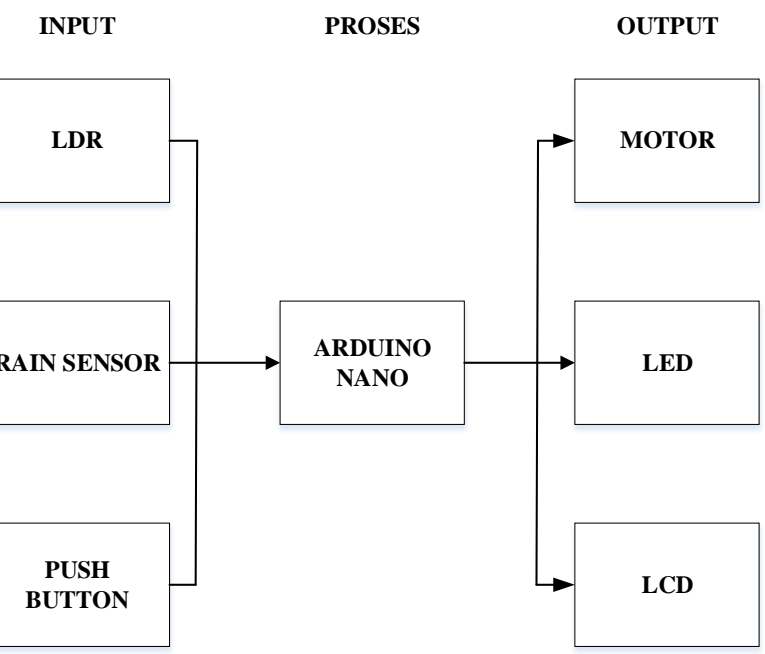

Gambar 11. Diagram Blok

Blok diagram system buka tutup atap stadion seperti pada Gambar.Catu daya yang digunakan memiliki tegangan keluaran $12 \mathrm{~V}$ Dc, kemudian diteruskan ke regulator tegangan 9V Dc dan 5,5 V DC, regulator tegangan $9 \mathrm{v}$ Dc digunakan untuk mensuplai tegangan ke Arduino. Hal ini dikarenakan Arduino telah memiliki regulator tegangan 5,5 V Dc dan 3,3 V DC dalam papab rangkaian. Sehingga apabila tegangan regulator internal Arduino memiliki tegangan dibawah 5,5 V DC. Karena tegangan pada Arduino. Regulator tegangan 5,5V DC yang diambil dari keluaran cat

udaya $12 \mathrm{~V}$ DC digunakan untuk mensuplai daya yang dibutuhkan oleh sensor LDR,Sensor hujan (Rain), LCD dan Push button. Sedangkan untuk motor dan ledstrip mengambil suplai dari catudaya yang memiliki tengangan $12 \mathrm{~V}$ DC

\section{HASIL DAN PEMBAHASAN}

A. Hasil Pengujian

1. Sensor Hujan (Rain)

Sensor hujan diletakkan diatap prototype stadion untuk dapat membaca kondisi hujan dengan cara meneteskan 1 sampai 3 tetes air diatas panel sensor yang telah tersambung ke pin Arduino, Panel sensor membaca nilai di atas $300 \mathrm{RH}$ maka 
keadaan tidak terjadi hujan dan ketika panel sensor membaca nilai di bawah $300 \mathrm{RH}$ maka keadaan terjadi hujan deras dan membaca delay selama 10 detik, lalu motor akan aktif menutup atap stadion selama 10 detik dan lampu akan menyala, dan sebaliknya jika kondisi panel sensor membaca nilai di atas $300 \mathrm{RH}$ maka keadaan maka motor aktif dan membuka atap stadion selama 10 detik dan lampu akan mati.

Tabel 1. Hasil Pengamatan Sensor Hujan

\begin{tabular}{|c|c|c|}
\hline No & Nilai Sensor Hujan & Keterangan \\
\hline 1 & 276 & Motor Aktif \\
\hline 2 & 257 & Motor Aktif \\
\hline 3 & 248 & Motor Aktif \\
\hline 4 & 229 & Motor Aktif \\
\hline 5 & 301 & Motor Tidak Aktif \\
\hline 6 & 342 & Motor Tidak Aktif \\
\hline 7 & 328 & Motor Tidak Aktif \\
\hline 8 & 315 & Motor Tidak Aktif \\
\hline
\end{tabular}

Berdasarkan hasil pembacaan di atas, panel sensor akan mendeteksi hujan deras dengan kondisi nilai menunjukkan di bawah $300 \mathrm{RH}$ sampai dengan $229 \mathrm{Rh}$ dan Ketika nillai pada suatu panel sensor diatas $300 \mathrm{RH}$ maka akan mendeteksi tidak terjadi hujan deras. Hal ini menunjukkan bahwa akses menutup dan membuka atap stadion hanya dapat dilakukkan Ketika nilai tersebut pada panel sensor pada kisaran nilai yang sudah diujikan.

\section{Sensor LDR}

Sensor LDR diletakkan pada samping atap stadion dimana berfungsi untuk membaca suatu intensitas cahaya dengan cara, Ketika suatu kondisis pada cahaya gelap, sensor akan membaca 10 detik yang telah tersambung pada pin Arduino. Sensor LDR ini akan memca kondisi cahaya yang gelap selama 10 detik untuk mengaktifkan motor stpper menutup atap stadion selama 10 detik dan lampu stadion akan aktif, Ketika sensor LDR membaca kondisi gelap kurang dari 10 detik maka tidak akan menyala, dan sebaliknya jika kondisi sensor ini LDR membaca dalam kondisi terang selama 10 detik maka motor akan terbuka selama 10 detik dan lampu akan mati

Tabel 2. Hasil Pengamatan Sensor Hujan

\begin{tabular}{|c|c|c|}
\hline No & $\begin{array}{c}\text { Hasil uji sensor } \\
\text { untuk LDR }\end{array}$ & $\begin{array}{c}\text { Hasil uji sensor LDR ke motor } \\
\text { stepper dan lampu }\end{array}$ \\
\hline 1 & 12 detik & Aktif dan Lampu Mneyala \\
\hline 2 & 15 detik & Aktif dan Lampu Mneyala \\
\hline 3 & 17 detik & Aktif dan Lampu Mneyala \\
\hline 4 & 22 detik & Aktif dan Lampu Mneyala \\
\hline 5 & 30 detik & Aktif dan Lampu Mneyala \\
\hline 6 & 45 detik & Aktif dan Lampu Mneyala \\
\hline 7 & 49 detik & Aktif dan Lampu Mneyala \\
\hline 8 & 9 detik & Tidak Aktif \\
\hline 9 & 7 detik & Tidak Aktif \\
\hline 10 & 5 detik & Tidak Aktif \\
\hline
\end{tabular}

Pada hasil diatas Ketika sensor LDR membaca kondisi cahaya gelap selama 10 detik maka motor stepper akan aktif menutup atap stadion dan lampu akan menyala dan Ketika sensor cahaya tidak mendeteksi cahaya gelap kurang dari 10 detik maka motor Stepper tidak akan aktif dannlampu tidak akan menyala. Ketika sensor LDR membava Intensitas cahaya terang selama 10 detik maka motor steper akan menutup dan lampu akan mati. Hal ini menujukkan bahwa akases membuka dan menutup atap stadion hanya dapat dilakukan Ketika intensitas cahaya pada sensor LDR kisaran cahaya yang telah diujikan.

3. Push Button

Dibawah ini merupakan pengujian pada push button yanng berfungsi sebagai pembuka gerbang secara manual. Saat push button buka ditekan maka akan mengirimkan data ke Arduino untuk memerintahkan motor bergerak membuka atap stadion dan saat push button tutup di tekan maka 
akan mengirimkan data ke Arduino untuk memrintahkan motor bergerak membuka atap stadion

Tabel 3. Hasil pengujian push Button buka dan tutup

\begin{tabular}{|c|c|c|c|}
\hline \multirow{2}{*}{ NO } & \multirow{2}{*}{ Kondisi } & \multicolumn{2}{|c|}{ Terbaca } \\
\cline { 3 - 4 } & & Pb Buka & PB tutup \\
\hline 1 & Tidak Ditekan & 1 & 1 \\
\hline 2 & Ditekan & 0 & 0 \\
\hline 3 & Tidak Ditekan & 1 & 1 \\
\hline 4 & Ditekan & 0 & 0 \\
\hline
\end{tabular}

Pengujian manual pada system buka tutp atap stadion ini merupakan push button sebagai input. Saat push Button tutup ditekan maka kan mengirmkan data ke Arduino untuk memerintahkan motor aktif selama 10 detik menutup atap stadion dan lampu akan menyala dan saat push button bukan ditekan maka akan mengirim data ke Arduino untuk memerintah motor aktif selama 10 detik dan mati

\section{B.Pembahasan}

Ketika sensor LDR membaca intensitas cahaya gelap maka motor akan aktif selama 10 detik menutup atap stadion dan ketika sensor membaca cahaya terang motor akan aktif selama 10 detik membuka atap stadion, sensor hujan membaca ketika terjadi kondisi nilai panel sensor membaca $284 \mathrm{RH}$ dalam kondisi hujan deras motor akan aktif 10 detik menutup atap stadion dan akan membuka ketika panel sensor membaca 326 RH dalam kondisi hujan tidak deras, dan pada saat kondisi manual, menutup dan terbukanya atap stadion dikendalikan oleh petugas stadion yang mana Ketika terjadi kondisi cuaca yang tidak bisa terdeteksi oleh mode otomatis. Dan selanjutnya petugas akan mengendalikan atap stadion dengan menekan push button tutup dan push button buka untuk mengaktifkan motor stepper untuk membuka atau menutup atap stadion selama 10 detik dan mengaktifkan lampu

\section{KESIMPULAN}

Berdasarkan hasil pengujian sistem yang telah dilaksanakan, maka dapat diambil kesimpulan sebagai berikut :

1. Sensor LDR membaca cahaya gelap selama 10 detik maka motor akan aktif untuk menutup atap stadion selama 10 detik dan lampu secara otomatis akan menyala untuk menerangi ruangan stadion. Kemudian saat sensor LDR membaca cahaya terang maka motor akan aktif untuk membuka atap stadion selama 10 detik dan lampu akan mati.

2. Sensor hujan menerima tetesan air dengan nilai kurang dari $300 \mathrm{RH}$ yang terbaca pada LCD maka motor akan aktif menutup atap stadion selama 10 detik dan lampu secara otomatis akan menyala. Dan ketika sensor hujan menerima tetesan air dengan nilai lebih dari $300 \mathrm{RH}$ yang terbaca pada LCD maka secara otomatis motor akan aktif membuka atap stadion selama 10 detik.

\section{DAFTAR PUSTAKA}

[1] Suryanto and E. S. R. Atmaja, "Atap Otomatis Tanaman Hidroponik Berbasis Mikrokontroler ATMega 89s52," JITK (Jurnal Ilmu Pengetah. dan Teknol. Komputer), vol. 3, no. 1, pp. 95-104, 2017.

[2] Y. Hendrian, Y. P. Yudatama, and V. S. Pratama, "Jemuran Otomatis Menggunakan Sensor LDR, Sensor Hujan Dan Sensor Kelembaban Berbasis Arduino Uno," J. Tek. Komput. AMIK BSI, vol. VI, no. 1, pp. 21-30, 2020, doi: 10.31294/jtk.v4i2.

[3] V. S. Pratama and Y. P. Yudatama, "Prototype Jemuran Otomatis Menggunakan Sensor LDR, Sensor Hujan Dan Sensor Kelembapan Berbasis Arduino Uno," J. Ilmu Pengetah. dan Teknol. 


\section{JEETech}

Journal Of Electrical Engineering And Technology

Komput., vol. 4, no. 1, pp. 91-98, 2018.

[4] D. Siswanto and S. Winardi, "Jemuran Pakaian Otomatis Menggunakan Sensor Hujan dan Sensor
LDR Berbasis Arduino Uno," J. Nar., vol. 1, no. 2, pp. 66-73, 2015. 